\title{
THIN NITRIDE LAYERS AS PERMEATION BARRIERS
}

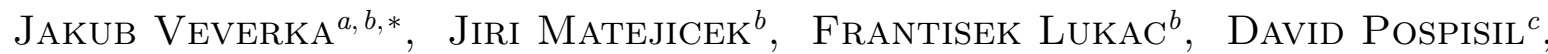 \\ Ladislav CvrceK ${ }^{d}$, Vincenc Nemanic ${ }^{e}$ \\ ${ }^{a}$ Faculty of Nuclear Sciences and Physical Engineering, Brehova 7, Praha 1, Czech Republic \\ ${ }^{b}$ Institute of Plasma Physics of the Czech Academy of Sciences, Za Slovankou 3, Praha 8, Czech Republic \\ ${ }^{c}$ Technical University of Liberec, Studentska 1402/2, Liberec I, Czech Republic \\ ${ }^{d}$ Department of Materials Engineering, Faculty of Mechanical Engineering, Czech Technical University in \\ Prague, Karlovo namesti 13, Praha 2, Czech Republic \\ e Jozef Stefan Institute, Jamova 39, Ljubljana, Slovenia \\ * corresponding author: veverka@ipp.cas.cz
}

\begin{abstract}
Permeation barriers represent one of the crucial fields in materials development for thermonuclear fusion. Primary objective of the barriers is to suppress the permeation of hydrogen isotopes (mainly tritium) from future thermonuclear fusion facilities. Secondary objective is to reduce hydrogen retention in structural materials, potentially also improving their corrosion resistance. Expected reactor conditions put high demands on the material, as well as on the final barrier quality. Key properties are tritium permeation reduction, absence of defects (especially cracks), high-temperature stability and corrosion resistance, and compatibility with structural materials (mostly ferritic-martensitic steels). Regarding industrial scale production, ability of the deposition method to coat large complex surfaces is desirable. Thin nitride layers, identified as promising permeation barriers, were prepared by diffusion-based nitridation and physical vapour deposition (PVD) and characterized.
\end{abstract}

KEYWORDS: permeation barriers, nitride layers, PVD coating, permeation measurement.

\section{INTRODUCTION}

Nuclear fusion is an appealing means of energy production that can resolve growing energy demands of the mankind. Facing inevitable exhaustion of fossil fuels and growing awareness of climate changes caused by greenhouse gases emissions, it is obvious that current means of energy production need to be replaced. Renewable sources (e.g. solar, hydro, wind or geothermal power) are not expected to be capable of supplying global energy needs. Therefore, entirely new source of energy is required, in an ideal case fulfilling the following criteria

- sufficient fuel supplies

- no harmful emissions

- no major operational hazards

Thermonuclear fusion expected to be harnessed in the first generation of power plants exhibits promising results regarding all the criteria. Energy production will be based on the following equations

$$
\begin{array}{r}
{ }_{1}^{2} \mathrm{D}+{ }_{1}^{3} \mathrm{~T} \longrightarrow{ }_{2}^{4} \mathrm{He}+{ }_{0}^{1} n+17.6 \mathrm{MeV} \\
{ }_{3}^{6} \mathrm{Li}+{ }_{0}^{1} n \longrightarrow{ }_{1}^{3} \mathrm{~T}+{ }_{2}^{4} \mathrm{He} .
\end{array}
$$

Abundance of deuterium and lithium is sufficient for thousands of years, tritium will be produced in-situ. Emissions consist only of harmless helium, operational hazards do not involve risk of uncontrolled chain reaction or major radiation leaks. However, enormous complexity and demands (technological, as well as economical) on the fusion facilities have delayed the harnessing of thermonuclear fusion. Joint international effort resulted in the construction of International Thermonuclear Experimental Reactor (ITER) that should demonstrate the feasibility of fusion and test the neccessary systems for future fusion power plants. Permeation barriers are one of the most important parts of fusion facility concerning radiological safety and economical issues. These are typically thin coatings that lower the permeation and retention of hydrogen isotopes (mainly tritium) in the reactor structures. Selected materials have to withstand harsh reactor conditions, including

- strong thermal gradients and elevated temperatures

- presence of significant neutron and secondary charged particle irradiation

- potential contact with high temperature PbLi (corrosion issues) - depending on the reactor design (further information to be found in [1])

Excessive tritium permeation could result in

- degradation of the reactor material properties

- radiological hazard during operation and decommisioning

- lowering of the reaction probability and economical losses

Therefore, the presence of a permeation barrier is envisaged by numerous studies [2 4] to meet the safety 
requirements of maximum allowable tritium losses ( $1 \mathrm{~g}$ per year) and maximum tritium inventory (200g) [1]. Permeation barriers are also essential for early and safe decommissioning of fusion facilities after their shutdown. Besides reducing the permeation through metallic structures, typically easily permeable by hydrogen isotopes, other material and deposition properties of the permeation barriers have to be taken into account:

- stability and reliability of the coating (regarding the abovementioned conditions)

- compatibility with the substrate material

- capability to form dense and defect-free layers on complex surfaces

Regarding the coating stability in corrosive environment, some studies show that, depending on the coolant and tritium breeder choice, fusion facility components can be subjected to corrosion attack up to $700 \mu \mathrm{m}$ per year, equal to $4 \mathrm{~kg}$ of dissolved material per year and square meter [5-7]. That would pose a significant risk to the structural integrity and operational reliability of the facility. Parts subjected to the corrosion attack are in most cases also threatened by tritium permeation, therefore the prospective coating ought to suppress both phenomena to a high extent. As candidate materials for the permeation barriers, commonly oxidic ceramics [2, 8] or nitrides [9, 10] are being studied. This study is focused on diffusion-based nitride layers, whose advantage lies in the applicability on large complex surfaces, including for example the inside of coolant tubes [11, 12. Such nitride layers are qualitatively compared to thin coatings prepared by physical vapour deposition (PVD), which is an established technology for the production of thin and dense coatings. On an industrial scale, large surface areas can be coated, including curved surfaces, but still it is primarily a line-of-sight coating technology.

Nitriding is a thermochemical treatment that consists of the introduction of nitrogen into metallic material. According to the method of nitrogen introduction, several nitriding techniques are being distinguished:

- gas nitriding

- plasma/ion nitriding

- solid/liquid nitriding

Gas nitriding [13] is conducted at elevated temperature, submitting the samples to nitrogen-containing atmosphere, commonly ammonia or various nitrogen mixtures, e.g. $\mathrm{H}_{2}$ and $\mathrm{N}_{2} ; \mathrm{N}_{2}, \mathrm{NH}_{3}$ and $\mathrm{CO}_{2}$ etc. Ion/plasma 14 nitriding uses a glow discharge to introduce nitrogen into the material; nitrogen ions are accelerated and impinge the surface. During solid nitriding [15], granulate containing nitrogen compound is used e.g. $\mathrm{Fe}_{4} \mathrm{KCN}$. The samples are surrounded by granulate and placed into heating oven for enhancing the diffusion.
Gas and plasma nitriding are well established and widely used and researched techniques, however the required facility is complicated. During gas nitriding, the process temperature may affect the hardness of the nitrided material. Plasma nitriding is faster than conventional gas nitriding and provides for a better control of the treatment parameters. This allows the control of the nitrided layer microstructure and also enables higher reproducibility of the results. Solid nitriding is a low-cost process in comparison to gas and plasma nitriding, when the only required facility is the furnace providing the heating. The heating generates atomic nitrogen that is able to diffuse into the material.

Nitriding promotes higher hardness of the specimen, increases wear resistance, fatigue resistance, corrosion resistance and, as it was observed, some nitrided materials have favourable permeation properties. Regardless of the used technique, surface cleaning of the samples is vital, because the contaminants can form a barrier preventing nitrogen from diffusing into the material. During the deposition, different layers are produced - diffusion and compound layer. Diffusion zone is a region characterized by solid solution in the original core microstructure with hardening precipitations. Compound layer typically consists of mixture of iron nitrides, in case of steel nitriding. With plasma nitriding, by controlling the process parameters, it is possible to determine the composition or even avoid the formation of the compound layer [16. In this study, three types of diffusion-nitrided layers were prepared and characterized for their morphology, phase and elemental composition and thermal stability. A brief comparison with several nitride coatings prepared by the PVD technique is made.

\section{EXPERIMENT}

As a substrate, ferritic-martensitic steel P92 was used, whose characteristic composition is provided in [17. It is very similar to EUROFER97 steel, developed as a reference structural material for the DEMO tokamak 18. Such material is also commonly used in permeation measurements [19], so a direct comparison with untreated substrate could be made. The substrates were prepared in a disk shape with $0.5 \mathrm{~mm}$ thickness and $25 \mathrm{~mm}$ diameter, by electrical discharge machining [20], grinding with sand paper and metallographic polishing. The following types of diffusionbased nitride layers were prepared:

- plasma nitridation $\left(430{ }^{\circ} \mathrm{C}, 24 \mathrm{~h}\right)$, at Technical University of Liberec

- carbonitridation $\left(560^{\circ} \mathrm{C}, 10 \mathrm{~h}\right)$ at Bodycote HT, s.r.o.

- salt nitridation $\left(530^{\circ} \mathrm{C}\right)$ at Katring Plus s.r.o.

Presence of the nitride layer and its elemental composition was investigated by Energy-dispersive X-ray Spectroscopy (EDS) in an EVO MA15 scanning electron 
microscope (Carl Zeiss SMA, Germany) equipped with a Quantax system and X-Flash 5010 detector (Bruker, Germany). Phase composition was analyzed by X-ray diffraction (XRD) using a D8 Discover diffractometer (Bruker, Germany). For the XRD measurements, Rietveld method was used to determine the composition. To assess thermal stability of the coatings, the samples were annealed in a vacuum furnace for 1 hour at $550{ }^{\circ} \mathrm{C}$, which is the foreseen temperature in the future reactor application, also used in the permeation measurements. After the annealing, the layer composition was verified again.

Additionally, six types of nitrides were deposited by PVD: WN, $\mathrm{CrN}$ and $\mathrm{Cr}_{2} \mathrm{~N}$ by magnetron sputtering at the Department of Materials Engineering (Faculty of Mechanical Engineering, Czech Technical University in Prague) and CrWN, CrAlN and ZrN by cathodic arc plasma deposition at IonBond Czechia s.r.o. Similar, but more comprehensive characterization was performed, including the permeation measurements at the facility of Jozef Stefan Institute in Ljubljana, Slovenia [21, 22. The details of the PVD coating preparation and characterization will be provided in a dedicated paper [23].

\section{Results}

\subsection{DifFUSION-NITRIDED LAYERS}

Surface morphology of the three layers is shown in Figure 1. A semi-granular structure consisting of very fine grains can be observed; in case of ion nitridation, these seem to be more concentrated along substrate grain boundaries. This appearance is typical and has been observed in previous studies [13, 24]. No cracks were observed, which would be detrimental for the permeation barrier performance. Thickness of the diffusion nitrided coatings, provided by the manufacturer, reached approximately 100nm. EDS and XRD measurements confirmed presence of the nitride layer. Elemental composition, as determined by EDS, is shown in Table 1 Phase composition, as determined by XRD, is shown in Table 2 Due to the low thickness of the nitride layer, the substrate is detected by both methods. Before additional characterizations, the samples were annealed to assess their thermal stability. However, XRD measurements after the annealing showed that the nitride layer was significantly decomposed. This can be seen in Figures 2 and 3 for the plasma-nitrided samples. Similar situation was observed for the carbonitrided and salt-nitrided samples. Therefore, permeation measurements of these coatings were not performed. In the plasma nitrided sample, a change in surface morphology was observed as well, including the formation of occassional cracks. This can be seen in Figure 4 For the carbonitrided and salt-nirided samples, the morphology remained very similar.
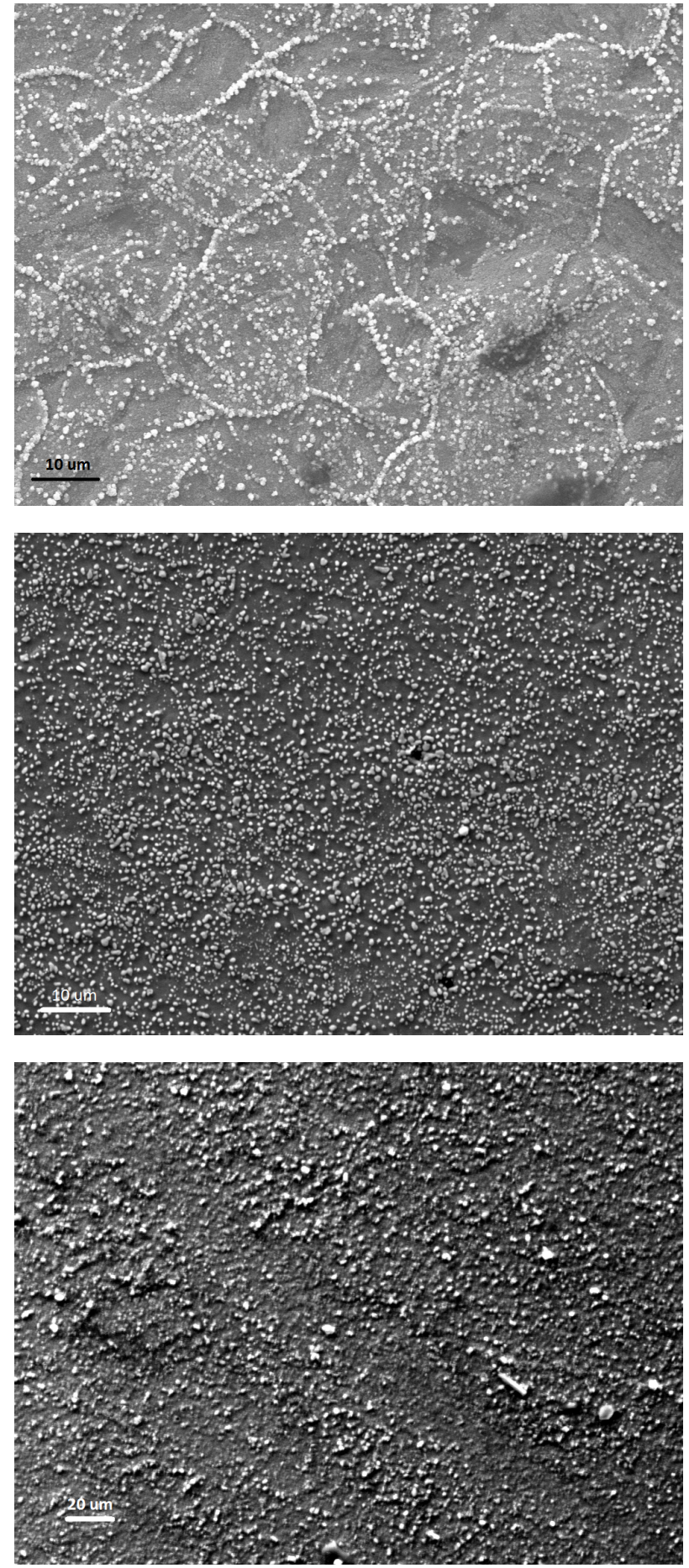

FIGURE 1. Surface morphologies of nitrided layers: plasma nitridation (top), carbonitridation (middle), salt nitridation (bottom).

\subsection{PVD COATINGS}

Successful deposition of the PVD coatings was confirmed by EDS and XRD measurements. Smooth and crack-free coatings were obtained, with thicknesses between 1.5 and $4.5 \mu \mathrm{m}$. Representative surface morphologies are shown in Figures 5 and 6 Scratch test showed good adhesion of the coatings. XRD measurements indicated all the PVD coatings to contain compressive stress, which is favorable as it suppresses 


\begin{tabular}{c|c|c|c|c|c|c|c|c|c|c}
\hline Fabrication method & $\mathrm{N}$ & $\mathrm{O}$ & $\mathrm{Na}$ & $\mathrm{Mg}$ & $\mathrm{Al}$ & $\mathrm{Cr}$ & $\mathrm{Fe}$ & $\mathrm{W}$ & $\mathrm{C}$ & $\mathrm{Si}$ \\
\hline \hline Plasma nitridation & 6.3 & 0.9 & & & & 9.6 & 81.9 & 1.3 & & \\
\hline Carbonitridation & 0.9 & 3.6 & & & 0.6 & 8.6 & 83.4 & 0.1 & 2.5 & 0.3 \\
\hline Salt nitridation & 0.1 & 21.2 & 1.0 & 0.2 & 0.8 & 6.2 & 70.1 & 0.4 & & \\
\hline
\end{tabular}

TABle 1. Composition of the nitride layers measured by EDS, wt. \%.

\begin{tabular}{c|c|c|c|c}
\hline Fabrication method & $\mathrm{Fe}_{2} \mathrm{~N}$ & $\mathrm{Fe}_{3} \mathrm{~N}$ & $\mathrm{Fe}_{4} \mathrm{~N}$ & Magnetite \\
\hline \hline Plasma nitridation & 14.96 & 18.27 & 4.88 & 0.00 \\
\hline Carbonitridation & 16.95 & 0.00 & 0.00 & 0.56 \\
\hline Salt nitridation & 27.20 & 4.09 & 0.00 & 17.79 \\
\hline
\end{tabular}

TABLE 2. Phase composition of the nitride layers measured by XRD, wt. $\%$ balance $\alpha$-Fe.

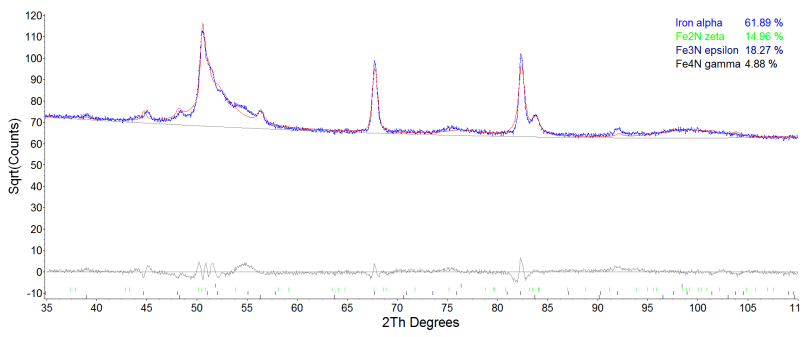

FigURE 2. XRD spectrum of the plasma nitrided sample.

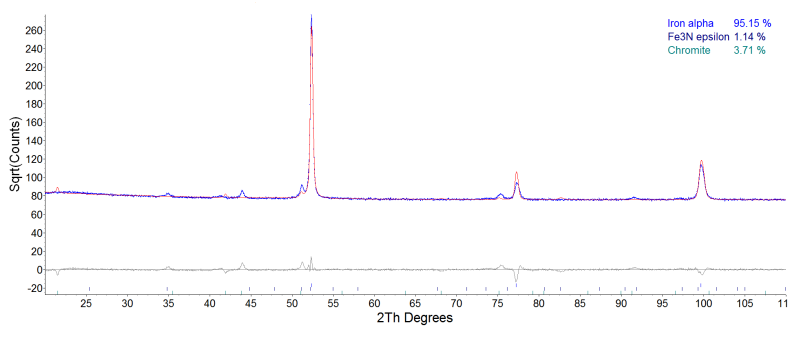

FIGURE 3. XRD spectrum of the plasma nitrided sample after thermal annealing.

crack propagation. All the PVD coatings showed potential for permeation barriers with permeation reduction factor $(\mathrm{PRF})>100$, in case of $\mathrm{ZrN}$ even $>10000$. Phase stability after the permeation test was verified again by XRD.

\section{Conclusions}

Thin nitride layers on P92 ferritic-martensitic steel were prepared by plasma nitridation, carbonitridation and salt nitridation. Formation of the nitride layer and its composition was determined by quantitative Rietveld analysis of diffraction patterns. SEM observations indicated the absence of surface cracking. However, after annealing at $550{ }^{\circ} \mathrm{C}$, the layers were significantly decomposed. Therefore, hydrogen permeation was not measured. PVD coatings of selected nitrides were also deposited on EUROFER97 ferriticmartensitic steel, a reference material for DEMO construction. The composition, thickness and adhesion of the coatings were measured and permeation measure-

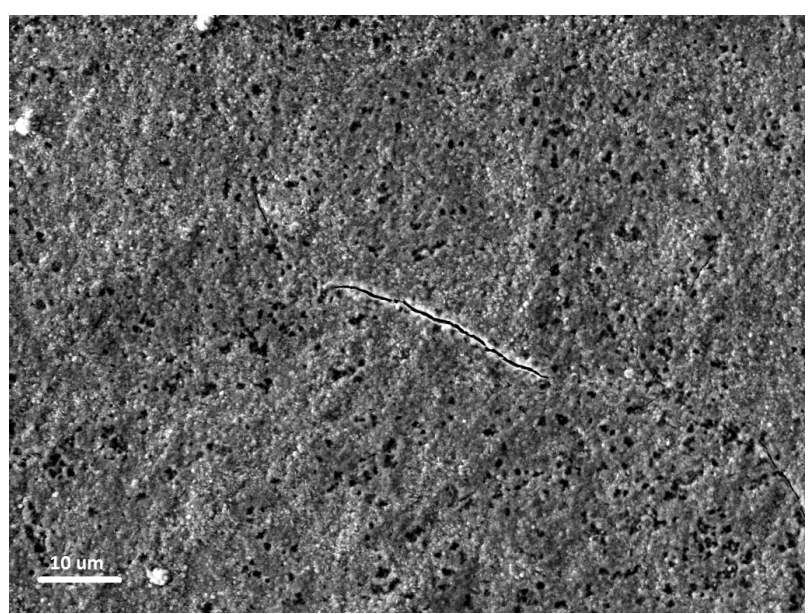

FiguRE 4. Surface morphology of plasma nitrided layer after thermal annealing.

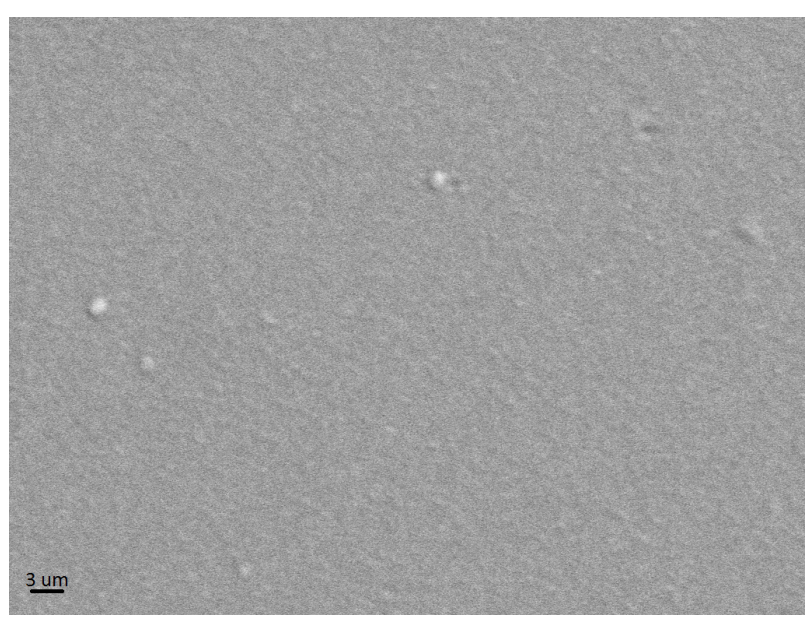

FiguRE 5. Surface morphology of magnetron sputtered CrN coating.

ments were performed. Thickness of the coatings was several $\mu \mathrm{m}$, all coatings showed the desired composition and good adhesion. Permeation measurements confirmed suitability of selected nitrides as permeation barriers. Best result was achieved by $\mathrm{ZrN}$ permeation reduction by three orders of magnitude. These coatings also demonstrated thermal stability at the test temperature. From these results, it can 


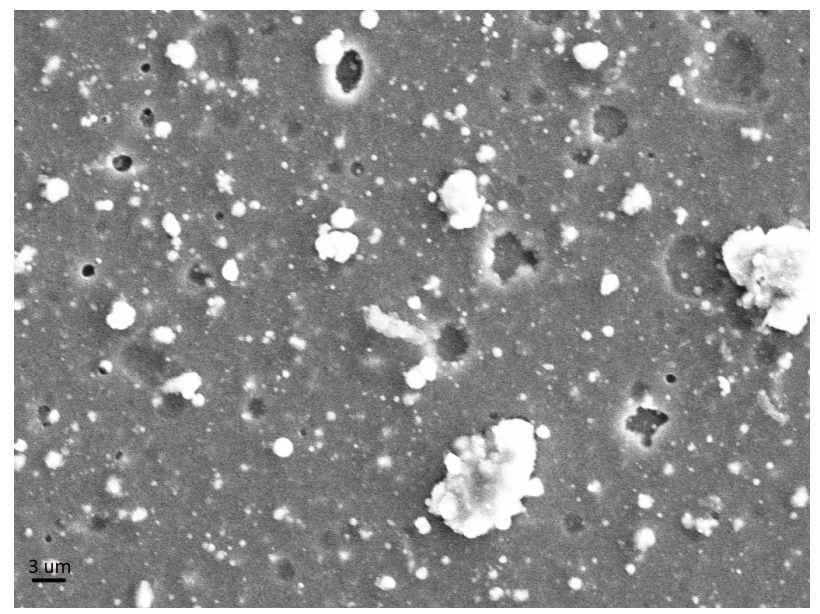

FiguRE 6. Surface morphology of cathodic arc plasma deposited CrAlN coating.

be concluded that the investigated diffusion-based nitride layers are not suitable for the application as permeation barriers at elevated temperature, due to the lack of thermal stability. From this point of view, as well as promising PRF values, PVD coatings seem more suitable. However, it should be noted that only a limited number of materials and techniques were examined and various other modifications exist, including technological parameter variations as well as different layer compositions.

\section{ACKNOWLEDGEMENTS}

This work has been carried out within the framework of the EUROfusion Consortium and has received funding from the Euratom research and training programme 20142018 under grant agreement No 633053. The views and opinions expressed herein do not necessarily reflect those of the European Commission.

Financial support from Czech Science Foundation (grant no. 14-12837), Czech Academy of Sciences (project Strategy AV21), Grant Agency of the Czech Technical University in Prague (grant No. SGS17/138/OHK4/2T/14) and Ministry of Education, Youth and Sport of the Czech Republic (program NPU1, project No. LO1207) is acknowledged.

\section{REFERENCES}

[1] L. Giancarli et al. Overview of the ITER TBM program. Fusion Engineering and Design 87:395-402, 2012.

[2] R. Causey et al. Tritium barriers and tritium diffusion in fusion reactors. Sandia National Laboratories 2009.

[3] M. Abdou et al. Blanket/first wall challenges and required $\mathrm{RD}$ on the pathway to DEMO. Fusion Engineering and Design 100:2-43, 2015.

[4] D. Demange et al. Tritium management and anti-permeation strategies for three different breeding blanket options foreseen for the european power plant physics and technology demonstration reactor study. Fusion Engineering and Design 89:1219-1222, 2014.

[5] W. Krauss et al. Al-based anti-corrosion and T-permeation barrier development for future DEMO blankets. Journal of Nuclear Materials 417:1233-1236, 2011.

[6] J. Konys et al. Corrosion behaviour of EUROFER steel in flowing eutectic Pb-17Li alloy. Journal of Nuclear Materials 329-333:1379-1383, 2004.

[7] J. Konys et al. Compatibility behaviour of EUROFER steel in flowing Pb-17Li. Journal of Nuclear Materials 386-388:678-681, 2009.

[8] H. Glasbrenner et al. Hydrogen permeation behaviour of hot-dip aluminized MANET steel. Fusion Technology 28:1159-1164, 1995.

[9] K. Forcey et al. The formation of tritium permeation barriers by CVD. Journal of Nuclear Materials 200:417-420, 1993.

[10] I. Tazhibaeva et al. Hydrogen permeation through steels and alloys with different protective coatings. Fusion Engineering and Design 51-52:199-205, 2000.

[11] X. Xiang et al. Preparation technique and alloying effect of aluminide coatings as tritium permeation barriers: A review. International Journal of Hydrogen Energy 40:3697-3707, 2015.

[12] T. Sample et al. The hydrogen permeation behaviour of aluminised coated martensitic steels under gaseous hydrogen, liquid $\mathrm{Pb}-17 \mathrm{Li} /$ hydrogen and cyclic thermal loads. Journal of Nuclear Materials 283-287:1272-1276, 2000.

[13] M. Kondo et al. Nitriding treatment of reduced activation ferritic steel as functional layer for liquid breeder blanket. Plasma and Fusion Research 6:2405117, 2011.

[14] Active screen plasma nitriding. [online], http://web.ald-vt.de/cms/vakuumtechnologie/technologien/vacuum-heattreatment/aspn-active-screen-plasma-nitriding/, 242017.

[15] M. Lee et al. A basic study on the solid-state nitriding of aluminum by mechanical alloying using a planetary ball mill. Advanced Powder Technology 8:291-299, 1997.

[16] C. Costa et al. Study of the nitrided layer obtained by different nitriding methods. Revista MatÃlria 20:460-465, 2015.

[17] P. Giroux et al. Mechanical and microtructural stability of P92 steel under unaxial tension at high temperature. Materials Science and Engineering A 527:3984-3993, 2010.

[18] Eurofer-97 technical specification. [online], www.uni-lj.si/mma/1-F4E-2008-GRT010.\%20Technical\%20Specification/2013070115554947/, 1122017.

[19] J. Engels et al. Hydrogen saturation and permeation barrier performance of yttrium oxide coatings. Fusion Engineering and Design 124:1140-1143, 2017.

[20] Sodick - wire EDM technology. [online], http://www.sodick.com/technology/wireedmtech, 1632017.

[21] V. Nemanic et al. Sensitivity enhancement in hydrogen permeation measurements. Journal of Vacuum Science and Technology A 28 (4):578-582, 2010. 
[22] V. Nemanic et al. Hydrogen permeation through silicon nitride films. Journal of Alloys and Compounds 539:184-189, 2012.

[23] J. Matejicek et al. Characterization of some less-common nitrides as permeation barriers, paper in preparation .
[24] B. Miao et al. The effect of sand blasting pretreatment on plasma nitriding. Vacuum 136:46-50, 2017. 